\title{
Local treatment with a polycarbophil-based cream in postmenopausal women with genitourinary syndrome of menopause
}

\author{
Tipatai Yodplob $^{1} \cdot$ Kun Sirisopana ${ }^{1} \cdot$ Mutita Jongwannasiri ${ }^{1} \cdot$ Pokket Sirisreetreerux $^{1} \cdot$ Wit Viseshsindh $^{1}$. \\ Wachira Kochakarn ${ }^{1}$
}

Received: 12 December 2019 / Accepted: 6 March 2020 / Published online: 23 March 2020

(C) The Author(s) 2020

\begin{abstract}
Introduction and hypothesis Genitourinary syndrome of menopause (GSM) is a common problem associated with lower urinary tract and gynecological symptoms due to the decrease in estrogen production in postmenopausal women. Topical estrogen therapy is shown to improve these symptoms; nonetheless, there are limited data on the efficacy of nonhormonal moisturizers in these patients.

Methods A prospective cohort study was conducted to compare the symptoms of GSM before and after treatment with a polycarbophil-based cream in 42 women. The quality of life (QoL) and sexual scores were obtained from the Thai version of the International Consultation on Incontinence Modular Questionnaire-Lower Urinary Tract Symptoms (ICIQ-LUTS) along with uroflow measurements before and 4 and 12 weeks after treatment.

Results Significant improvements in ICIQ-LUTSqol scores were observed after 4 weeks $(9.38 \pm 7.47$ vs $6.76 \pm 5.77 ; p=0.017)$ and 12 weeks $(10.03 \pm 7.49$ vs $5.97 \pm 4.02 ; p=0.002)$ when compared with the baseline values before treatment. The ICIQLUTS sexual scores were also improved after treatment at 4 weeks $(2.29 \pm 2.26$ vs $0.88 \pm 1.34 ; p<0.001)$ and 12 weeks $(2.13 \pm$ 2.22 vs $0.42 \pm 0.81 ; p<0.001)$ compared with the baseline scores. No differences in ICIQ-LUTSqol and sexual scores were observed between the 4- and 12-week treatment groups.

Conclusion The polycarbophil-based cream improved the overall LUTS and sexual symptoms in the patients with GSM, thus indicating that the nonhormonal polycarbophil-based cream may prove effective for the treatment for women with this condition.
\end{abstract}

Keywords Genitourinary syndrome of menopause · Vaginal moisturizer · Vaginal lubricant · Polycarbophil-based cream · Vaginal dryness · Vulvovaginal atrophy

\section{Introduction}

Genitourinary syndrome of menopause (GSM) is a common problem in postmenopausal women with a prevalence of about 50\% [1-3]. The pathophysiology of this syndrome is due to the decrease in estrogen production from both ovaries in postmenopausal women. Estrogen depletion affects several organs, including the vaginal and urethral mucosae, leading to a reduction in vaginal secretion, thinning of the vaginal and

Wit Viseshsindh

wituro101@gmail.com

1 Division of Urology, Department of Surgery, Faculty of Medicine, Ramathibodi Hospital, Mahidol University, Bangkok, Thailand urethral mucosae, and vaginal dryness, inflammation, and obstruction. Patients with this syndrome usually develop lower urinary tract symptoms, including increased urinary urgency and frequency, nocturia, urinary incontinence, urinary tract infection, vaginal dryness and irritation, and dyspareunia [4]. These symptoms are bothersome and affect the patients' quality of life (QoL) [5].

Genitourinary syndrome of menopause is clinically diagnosed by obtaining the clinical history of the patient and by conducting physical and pelvic examinations. The common pelvic examination findings in patients with GSM as a result of estrogen depletion are vaginal dryness, loss of vaginal rugae, increased vaginal $\mathrm{pH}$, leukorrhea, urethral or vaginal atrophy, meatal stenosis, and urethral prolapse. Subject-reported symptoms and clinical findings were categorized into three groups, external genitalia symptoms (vaginal dryness, pruritus 
vulva, leukorrhea), sexual symptoms (loss of libido, dyspareunia, bleeding during intercourse), and urological symptoms (urgency, frequency, nocturia, urinary tract infection) [6].

The treatment of GSM can be classified into two types [3, 6]: hormone replacement therapy, which can be further divided into systemic and local preparations, and nonhormonal therapy, which includes lifestyle modifications and the use of steroids, laser therapy, or vaginal moisturizers $[3,7,8]$. Previous studies have revealed that local hormone replacement therapy significantly improves the symptoms of patients with GSM $[9,10]$.

A polycarbophil-based cream is a hormone-free vaginal moisturizer composed of purified water $(78.82 \%)$, polycarbophil, carbopol, glycerol, mineral oil, hydrogenated palm oil, glycerides, and sorbic acid. Previous studies have demonstrated the safety of this cream in the absence of any cytotoxic effects [11-13]. However, studies on the efficacy of the polycarbophil-based cream in terms of improvements in urinary symptoms are limited. The primary objective of this study was to evaluate the efficacy of this cream for the treatment of GSM, and the secondary objective was to assess the changes in uroflowmetry after the treatment. Our hypothesis is that nonhormonal polycarbophil-based cream will improve the symptoms in this group of patients.

\section{Materials and methods}

Our study is a prospective single-cohort study. Approval for the study was obtained from the Committee for Research at the Faculty of Medicine, Ramathibodi Hospital, Mahidol University. All inclusion criteria had to be met as follows: women with one or more external genitalia or sexual symptoms; those with one or more urinary symptoms; and those who agreed to participate in this study. Patients who were allergic to polycarbophil-based cream, could not undergo uroflowmetry, and had been treated with a topical estrogen cream or vaginal moisturizer within 3 months prior to this study were excluded.

Forty-four women diagnosed with GSM between July 2017 and October 2018 were asked to participate in this study. Two of them were excluded because they refused to participate in this study. All 42 women were treated with a topical vaginal polycarbophil-based moisturizing cream. The patients were instructed to apply the topical vaginal moisturizer to the vagina and urethral opening once every 3 days before bedtime.

At the beginning of the study, data comprising the clinical characteristics of the patients, such as age, weight, height, body mass index (BMI), last menstrual period, and clinical symptoms of GSM (external genitalia symptoms, sexual symptoms, and urological symptoms), were collected. Baseline QoL and sexual scores of the Thai version of the International Consultation on Incontinence Modular Questionnaire-Lower Urinary Tract Symptoms (ICIQ-LUTS) [14] were collected directly by a doctor to evaluate the pretreatment symptom score. These questionnaires are composed of ascaling score of 1-10 to evaluate each urological, QoL and sexual symptom with a total of 22 questions. Uroflowmetry (Aquarius TT Laborie $®$ ) was performed in all the patients to evaluate the maximum urine flow and the void, as well as PVR urine volume. Uroflowmetry was evaluated using spontaneous void volume. PVR was measured by bladder scan (PORTASCANTM3D). All patients were informed about the study follow-up protocol and were encouraged to co-operate with the schedule. A few days before follow-up, patients were called by phone to remind them about the appointment. After 4 and 12 weeks of treatment, the patients were instructed to visit the outpatient department to re-evaluate the ICIQ-LUTSqol score, ICIQ-LUTSsex score, and uroflowmetry results. A flow chart of the study design is presented in Fig. 1.

The characteristics of the patients with the continuous variables are expressed as mean \pm standard deviation (SD), and the categorical variables are expressed as frequency (\%). The scores of the ICIQ-LUTSqol, ICIQ-LUTSsex, and uroflowmetry before and after treatment (4 and 12 weeks) with the polycarbophil-based cream were compared using the paired $t$ test. Statistical analysis was conducted using the STATA program version 14 (StataCorp, College Station, TX, USA). The significance value ( $p$ value) was set at $<0.05$.

\section{Results}

Baseline data were collected on 42 postmenopausal women (age, $66.08 \pm 9.20$ years; BMI, $24.05 \pm 3.19 \mathrm{~kg} / \mathrm{m}^{2}$; and duration of menopause, $17.68 \pm 9.93$ years from onset). Before treatment, the overall and bother baseline ICIQ-LUSqol scores were $9.38 \pm 7.47$ and $28.26 \pm 24.15$ respectively, whereas the corresponding ICIQ-LUTSsex scores were 2.29 \pm 2.46 and $6.09 \pm 6.92$ respectively. The uroflowmetry values for void volume, maximum flow rate, and PVR urine volume were $261.59 \pm 158.70 \mathrm{ml}, 21.69 \pm 10.74 \mathrm{ml} / \mathrm{s}$, and $31.82 \pm$ $41.01 \mathrm{ml}$ respectively (Table 1).

After 4 weeks of treatment with the polycarbophil-based cream, the mean \pm SD overall ICIQ-LUTSqol score was significantly improved from a baseline $(n=34)$ of $9.38 \pm 7.47$ to $6.76 \pm 5.77(p=0.017)$, and the bother score was significantly improved from $28.26 \pm 24.15$ to $20.18 \pm 21.33(p=0.025$; Table 2). Likewise, the mean overall and bother ICIQLUTSsex scores were significantly improved, from $2.29 \pm$ 2.46 to $0.88 \pm 1.34(p<0.001)$ and from $6.09 \pm 6.92$ to 2.12 $\pm 3.46(p<0.001)$ respectively. As presented in Table 2, no significant changes in void volume and maximum flow were observed, whereas the PVR urine was significantly increased $(p=0.028)$ after use of the cream. 
Fig. 1 Flow chart of the study design. ICIQ-LUTS International Consultation on Incontinence Modular Questionnaire-Lower Urinary Tract Symptoms, ICIQFLUTS International Consultation on Incontinence Questionnaire Female Lower Urinary Tract Symptoms Modules, qoL quality of life

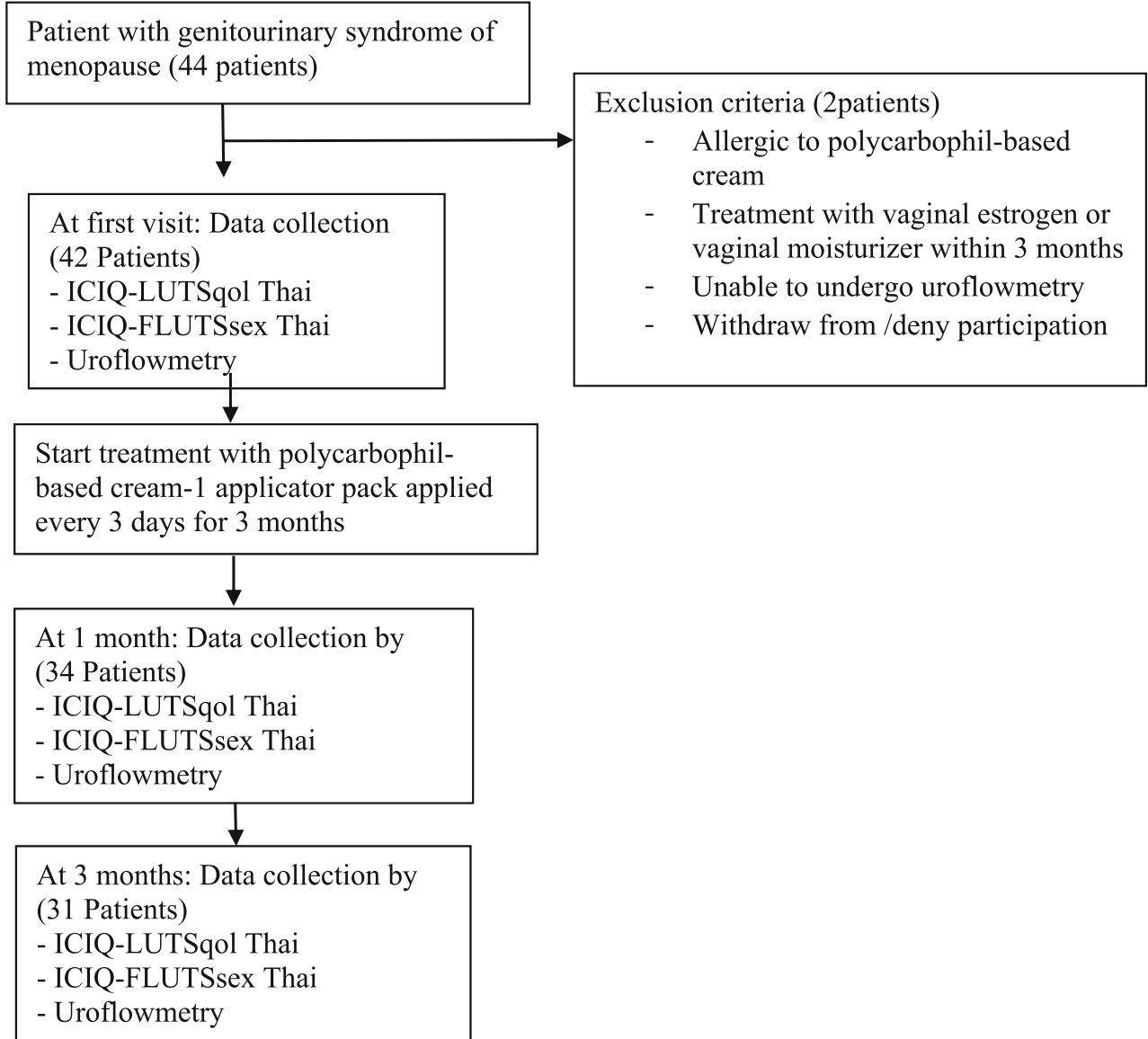

Note: . ICIQ-LUTS, International Consultation on Incontinence Modular Questionnaire-Lower Urinary Tract Symptoms; qoL, quality of life
After 12 weeks of treatment with the cream, the mean overall and bother ICIQ-LUTSqol scores were significantly improved from a baseline $(n=34)$ of $10.03 \pm 7.49$ to $5.97 \pm$ $4.02(p=0.002)$ and from $30.61 \pm 23.99$ to $18.77 \pm 17.19(p=$ $0.004)$ respectively. Significant improvements in the mean overall ICIQ-LUTSsex score from $2.13 \pm 2.22$ to $0.42 \pm 0.81$ $(p<0.001)$ and the mean bother score from $5.65 \pm 6.36$ to $1.06 \pm 1.75(p<0.001)$ were observed. Furthermore, no significant changes in PVR urine maximum flow rate were noted; alternatively, the void volume was significantly increased from $246.93 \pm 156.06$ to $298.87 \pm 148.11$ ( $p=0.038$; Table 2).

No significant differences in scores were observed between 4 and 12 weeks of treatment, except for the PVR urine, which was significantly decreased from $53.74 \pm 63.37$ to $36.97 \pm$ $43.88(p=0.022$; Table 3).

\section{Discussion}

The main objectives of localized GSM treatment to alleviate the genital symptoms and to restore the vaginal environment to its normal healthy condition. Although vaginal estrogen therapy is effective for the treatment of GSM $[10,15,16]$. In patients with estrogen-sensitive malignancy, use of the nonhormone-based moisturizers and lubricants is considered first-line therapy, whereas estrogenized therapies are reserved for those women whose symptoms are refractory to first-line treatment [17-24]. Vaginal moisturizers rehydrate the dry mucosal tissue; they are absorbed into the skin and adhere to the vaginal lining, thereby mimicking natural vaginal secretions by changing the fluid content of the endothelium and lowering the vaginal $\mathrm{pH}$ [9].

In a previous study, Origoni et al. [25] demonstrated significant improvements in the symptoms of patients with GSM, both objectively (using the vaginal health index) and subjectively (using the visual analog scale), after 2 months of treatment with a hyaluronic acid-based vaginal lubricant. In addition, a significant improvement in the QoL of these patients was reported with a patient satisfaction score of $95 \%$ at the end of their study. The findings of the current study are in agreement with the 
Table 1 Baseline subject and clinical characteristics

\begin{tabular}{ll}
\hline Characteristic & Data \\
\hline Demographics $(N=42)$ & \\
Age (years), mean \pm SD & $66.08 \pm 9.20$ \\
Body weight $(\mathrm{kg})$, mean $\pm \mathrm{SD}$ & $57.38 \pm 8.37$ \\
Height $(\mathrm{cm})$, mean $\pm \mathrm{SD}$ & $154.41 \pm 5.86$ \\
BMI $\left(\mathrm{kg} / \mathrm{m}^{2}\right)$, mean $\pm \mathrm{SD}$ & $24.05 \pm 3.19$ \\
Menstruation period (years), mean $\pm \mathrm{SD}$ & $17.68 \pm 9.93$ \\
External genitalia, $n(\%)$ & \\
Dryness & $38(90.48)$ \\
Irritation/burning & $17(40.48)$ \\
Tenderness & $4(9.52)$ \\
Pruritic vulvae & $3(7.14)$ \\
Leukorrhea & $6(14.29)$ \\
Erythema & $1(2.38)$ \\
Fusion of labia & $1(2.38)$ \\
Sexual, $n(\%)$ & \\
Loss of libido & $2(16.67)$ \\
Loss of arousal & $1(8.33)$ \\
Lack of lubrication & $5(41.67)$ \\
Dyspareunia & $6(50.00)$ \\
Dysorgasmia & $1(8.33)$ \\
Pelvic pain & $1(8.33)$ \\
Urological, $n(\%)$ & \\
Frequency & $22(52.38)$ \\
Urgency & $16(38.10)$ \\
Nocturia & $36(85.71)$ \\
Dysuria & $8(19.05)$ \\
Hematuria & $1(2.38)$ \\
SUI/UUI & $22(52.38)$ \\
Post-void dribbling & $3(7.14)$ \\
Recurrent & $1(2.38)$ \\
\hline
\end{tabular}

BMI body mass index, SUI stress urinary incontinence, UUI urge urinary incontinence results of the aforementioned study; significant improvements in both QoL and sexual symptoms were observed after 4 weeks of treatment with the vaginal moisturizer in the present study. These improvements were also observed 12 weeks after the treatment.

The void volume was significantly increased after 12 weeks of treatment. However, the maximum urine flow rate was not significantly altered after 4 and 12 weeks of treatment. Although PVR urine was significantly increased after 4 weeks of treatment when compared with the baseline values, these changes might not be clinically significant.

A strength of this study is that its prospective design. Also, the study uses validated questionnaires to evaluate patients' symptoms as well as good patient compliance and follow-up. A limitation of the study was that comparisons between the use of a placebo and standard treatment (hormonal vaginal preparation) were not made in this study, as it might have been difficult to interpret the true efficacy of the treatment method and lack of control group of women without treatment in this study. The study was focus on voiding and sexual symptoms but less on gynecological symptoms. Additional well-designed randomized controlled studies are warranted.

\section{Conclusion}

Use of nonhormonal vagina polycarbophil-based moisturizing cream for the treatment of genitourinary symptoms of menopause resulted in significant improvements in validated lower urinary tract and sexual quality of life measures. This study
Table 2 Comparison of mean International Consultation on Incontinence Modular Questionnaire (ICIQ) scores and uroflowmetry parameters before and after (4 weeks and 12 weeks) treatment with the polycarbophilbased cream

\begin{tabular}{|c|c|c|c|c|c|}
\hline & $\begin{array}{l}\text { Before treatment } \\
(n=34)\end{array}$ & $\begin{array}{l}\text { 4th week } \\
(n=34)\end{array}$ & $p$ value & $\begin{array}{l}\text { 12th week } \\
(n=31)\end{array}$ & $p$ value \\
\hline \multicolumn{6}{|c|}{ ICIQ-LUTSqol Thai (mean \pm SD) } \\
\hline Overall score & $9.38 \pm 7.47$ & $6.76 \pm 5.77$ & $0.017 *$ & $5.97 \pm 4.02$ & $0.002 *$ \\
\hline Bother score & $28.26 \pm 24.15$ & $20.18 \pm 21.33$ & $0.025 *$ & $18.77 \pm 17.19$ & $0.004^{*}$ \\
\hline \multicolumn{6}{|c|}{ ICIQ-LUTSsex Thai (mean \pm SD) } \\
\hline Overall score & $2.29 \pm 2.46$ & $0.88 \pm 1.34$ & $<0.001 *$ & $0.42 \pm 0.81$ & $<0.001 *$ \\
\hline Bother score & $6.09 \pm 6.92$ & $2.12 \pm 3.46$ & $<0.001 *$ & $1.06 \pm 1.75$ & $<0.001 *$ \\
\hline \multicolumn{6}{|c|}{ Uroflowmetry (mean $\pm \mathrm{SD}$ ) } \\
\hline $\begin{array}{l}\text { Void volume } \\
(\mathrm{ml})\end{array}$ & $261.59 \pm 158.70$ & $296.78 \pm 139.39$ & 0.232 & $298.87 \pm 148.11$ & $\mathbf{0 . 0 3 8}^{*}$ \\
\hline Qmax (ml/s) & $21.69 \pm 10.74$ & $23.12 \pm 9.91$ & 0.087 & $22.73 \pm 10.47$ & 0.093 \\
\hline PVR (ml) & $31.82 \pm 41.01$ & $52.15 \pm 60.66$ & $0.028 *$ & $36.97 \pm 43.88$ & 0.378 \\
\hline
\end{tabular}

Boldfaced $p$ value denotes statistical significance $(p<0.05)$ at both the 4th week and the 12 th week compared with baseline

Qmax maximum urine flow rate, $P V R$ post-void residual urine Volume, $S D$ standard deviation

*Comparison between groups using the paired $t$ test 
Table 3 Comparison of mean International Consultation on Incontinence Modular Questionnaire (ICIQ) scores and uroflowmetry parameters between 4 and 12 weeks of treatment

$$
\text { 4th week }(n=31) \quad 12 \text { th week }(n=31) \quad p \text { value }
$$

\begin{tabular}{|c|c|c|c|}
\hline \multicolumn{4}{|c|}{ ICIQ-LUTSqol Thai (mean \pm SD) } \\
\hline Overall score & $7.06 \pm 5.89$ & $5.97 \pm 4.02$ & 0.236 \\
\hline Bother score & $21.48 \pm 21.84$ & $18.77 \pm 17.19$ & 0.310 \\
\hline \multicolumn{4}{|c|}{ ICIQ-FLUTSsex Thai (mean \pm SD) } \\
\hline Overall score & $0.68 \pm 1.14$ & $0.42 \pm 0.81$ & 0.174 \\
\hline Bother score & $1.74 \pm 3.23$ & $1.06 \pm 1.75$ & 0.112 \\
\hline \multicolumn{4}{|c|}{ Uroflowmetry (mean $\pm \mathrm{SD})$} \\
\hline Void volume (ml) & $291.23 \pm 128.65$ & $298.87 \pm 148.11$ & 0.715 \\
\hline $\mathrm{Qmax}(\mathrm{ml} / \mathrm{s})$ & $22.84 \pm 9.82$ & $22.73 \pm 10.47$ & 0.899 \\
\hline PVR (ml) & $53.74 \pm 63.37$ & $36.97 \pm 43.88$ & $0.022 *$ \\
\hline
\end{tabular}

Boldfaced $p$ value denotes statistical significance $(p<0.05)$

Qmax maximum urine flow rate, $P V R$ post-void residual urine volume, $S D$ standard deviation

*Paired $t$ test

suggests that a nonhormonal vaginal polycarbophil-based moisturizing cream might be effective for the treatment of patients with GSM.

Acknowledgements This work was supported by Wijittra Matang, Yada Phengsalae, and Kornkanok Somboonpun. The authors thank Wijittra Matang, Yada Phengsalae, and Kornkanok Somboonpun for continuing support and encouragement.

Authors' contributions T.Y.: project development, data collection, manuscript writing; K.S.: data collection, data analysis; M.J.: data collection; P.S.: data collection, data analysis, manuscript writing; W.V.: project development, data collection, data analysis; W.K.: data collection, data analysis.

Funding Our funding source was the Division of Urology, Department of Surgery, Faculty of Medicine, Ramathibodi Hospital, Mahidol University.

\section{Compliance with ethical standards}

\section{Conflicts of interest None.}

Open Access This article is licensed under a Creative Commons Attribution 4.0 International License, which permits use, sharing, adaptation, distribution and reproduction in any medium or format, as long as you give appropriate credit to the original author(s) and the source, provide a link to the Creative Commons licence, and indicate if changes were made. The images or other third party material in this article are included in the article's Creative Commons licence, unless indicated otherwise in a credit line to the material. If material is not included in the article's Creative Commons licence and your intended use is not permitted by statutory regulation or exceeds the permitted use, you will need to obtain permission directly from the copyright holder. To view a copy of this licence, visit http://creativecommons.org/licenses/by/4.0/.

\section{References}

1. Chua Y, Limpaphayom KK, Cheng B, et al. Genitourinary syndrome of menopause in five Asian countries: results from the pan-Asian REVIVE survey. Climacteric. 2017;20:367-73.

2. Nappi RE, Palacios S, Panay N, Particco M, Krychman ML. Vulvar and vaginal atrophy in four European countries: evidence from the European REVIVE survey. Climacteric. 2016;19:188-97.

3. American College of Obstetricians and Gynecologists. Management of menopausal symptoms. Practice Bulletin No. 141. Obstet Gynecol 2014;123:202-16.

4. Portman DJ, Gass ML. Genitourinary syndrome of menopause: new terminology for vulvovaginal atrophy from the International Society for the Study of Women's Sexual Health and the North American Menopause Society. Menopause. 2014;21:1063-8.

5. Barlow DH, Cardozo LD, Francis RM, et al. Urogenital ageing and its effect on sexual health in older British women. Br J Obstet Gynaecol. 1997;104:10487-91.

6. Gandhi J, Chen A, Dagur G, et al. Genitourinary syndrome of menopause: an overview of clinical manifestations, pathophysiology, etiology, evaluation, and management. Am J Obstet Gynecol. 2016;215:704-11.

7. Edwards D, Panay N. Treating vulvovaginal atrophy/genitourinary syndrome of menopause: how important is vaginal lubricant and moisturizer composition? Climacteric. 2016;19:151-61.

8. Willhite LA, O'Connell MB. Urogenital atrophy: prevention and treatment. Pharmacotherapy. 2001;21:464-80.

9. Chuery AC, Speck NM, de Moura KF, Belfort PN, Sakano C, Ribalta JC. Efficacy of vaginal use of topical estriol in postmenopausal women with urogenital atrophy. Clin Exp Obstet Gynecol. 2011;38:143-5.

10. Simunic V, Banovic I, Ciglar S, Jeren L, Pavicic Baldani D, Sprem M. Local estrogen treatment in patients with urogenital symptoms. Int J Gynaecol Obstet. 2003;82:187-97.

11. Cunha AR, Machado RM, Palmeira-de-Oliveira A, Martinez-deOliveira J, das Neves J, Palmeira-de-Oliveira R. Characterization of commercially available vaginal lubricants: a safety perspective. Pharmaceutics. 2014;6:530-42.

12. Genazzani AD, Milani M (2017) Postmenopausal vaginal atrophy: non-hormonal therapy with a moisturizing bioadhesive vaginal http://www.womenshealthcaresolutions.com/asset/pdf/ postmenopausal_vaginal_atrophy.pdf. Assessed 18 Sept 2017.

13. Loprinzi CL, Abu-Ghazaleh S, Sloan JA, van Haelst-Pisani C, Hammer AM, Rowland KM Jr, et al. Phase III randomized double-blind study to evaluate the efficacy of a polycarbophilbased vaginal moisturizer in women with breast cancer. J Clin Oncol. 1997 Mar;15(3):969-73.

14. Abrams P, Avery K, Gardener N, Donovan J, Board IA. The International Consultation on Incontinence Modular Questionnaire. J Urol. 2006;175:1063-6.

15. Portman D, Palacios S, Re N, Mueck AO. Ospemifene, a nonestrogen selective estrogen receptor modulator for the treatment of vaginal dryness associated with postmenopausal vulvar and vaginal atrophy: a randomised, placebo-controlled, phase III trial. Maturitas. 2014;78:91-8.

16. Suckling JA, Kennedy R, Lethaby A, Roberts H. Local oestrogen for vaginal atrophy in postmenopausal women. Cochrane Database Syst Rev 2006;(4):CD001500. https://doi.org/10.1002/14651858. CD001500.pub2.

17. Ponzone R, Biglia N, Jacomuzzi ME, Maggiorotto F, Mariani L, Sismondi P. Vaginal oestrogen therapy after breast cancer: is it safe? Eur J Cancer. 2005;41:2673-81.

18. Le Ray I, Dell'Aniello S, Bonnetain F, Azoulay L, Suissa S. Local estrogen therapy and risk of breast cancer recurrence among 
hormone-treated patients: a nested case-control study. Breast Cancer Res Treat. 2012;135:603-9.

19. O'Meara ES, Rossing MA, Daling JR, Elmore JG, Barlow WE, Weiss NS. Hormone replacement therapy after a diagnosis of breast cancer in relation to recurrence and mortality. J Natl Cancer Inst. 2001;93:754-62.

20. Trinkaus M, Chin S, Wolfman W, Simmons C, Clemons M. Should urogenital atrophy in breast cancer survivors be treated with topical estrogens? Oncologist. 2008;13:222-31.

21. Biglia N, Peano E, Sgandurra P, Moggio G, Panuccio E, Migliardi $\mathrm{M}$, et al. Low-dose vaginal estrogens or vaginal moisturizer in breast cancer survivors with urogenital atrophy: a preliminary study. Gynecol Endocrinol. 2010;26:404-12.

22. American College of Obstetricians and Gynecologists. Management of gynecologic issues in women with breast cancer. Practice Bulletin No. 126. Obstet Gynecol 2012; 119:666-82.
23. Wills S, Ravipati A, Venuturumilli P, et al. Effects of vaginal estrogens on serum estradiol levels in postmenopausal breast cancer survivors and women at risk of breast cancer taking an aromatase inhibitor or a selective estrogen receptor modulator. J Oncol Pract. 2012;8:144-8.

24. Farrell R. ACOG Committee opinion no. 659: the use of vaginal estrogen in women with a history of estrogen-dependent breast cancer. Obstet Gynecol. 2016;127(3):e93-6.

25. Origoni M, Cimmino C, Carminati G, Iachini E, Stefani C, Girardelli S, et al. Postmenopausal vulvovaginal atrophy (VVA) is positively improved by topical hyaluronic acid application. A prospective, observational study. Eur Rev Med Pharmacol Sci. 2016;20:4190-5.

Publisher's note Springer Nature remains neutral with regard to jurisdictional claims in published maps and institutional affiliations. 